\title{
Thermal Response Study of Carbon Epoxy Laminates Exposed to Fire
}

\author{
Han Li ${ }^{1,2, *}$,Baoxin Fan ${ }^{2}$, Nasidan Wang ${ }^{2}$, Xuefei Han ${ }^{2}$, Zhenyu Feng ${ }^{2}$ and Shijun Guo ${ }^{1,3}$ \\ 1 School of Mechatronical Engineering, Beijing Institute of Technology, Beijing 100081, China \\ 2 College of Airworthiness, Civil Aviation University of China, Tianjin 300300, China \\ 3 Centre of Aeronautics, Cranfield University, Bedfordshire MK43 0AL, UK \\ * Correspondence: cauc_lihan@126.com
}

\begin{abstract}
In this paper, a three-dimensional thermal response model is developed to investigate the thermal behavior of carbon epoxy composite impacted directly by propane flame. The model is established in consideration of heat transfer and energy conservation in which the heat transfer is in the form of anisotropic heat conduction, absorption by matrix decomposition and diffusion of gas. Arrhenius equation is utilized to present the decomposition process of the materials. The diffusion equation for the decomposition gas is included for mass conservation. The thermal response model is implemented with the UMATHT and USDFLD subroutines via ABAQUS code, from which the temperature, density, decomposition degree and decomposition rate can be extracted to analysis the process of material decomposition by finite element simulation. The model shows its capability to analysis the evolution of a carbon epoxy composite in fire by the comparison between the numerical and experimental results. Furthermore, the numerical results show that thermal conductivities in different directions of fiber have a significant influence on the heat transfer. In addition, the relationship between the decomposition degree and temperature is correlated with depths, as well as the peak value of decomposition rate and the time to reach that.
\end{abstract}

Keywords: thermal response; carbon fiber reinforced epoxy laminates; decomposition; finite element analysis

\section{Introduction}

In recent years, carbon fiber reinforced polymer (CFRP) composites have been widely used to construct components of airplane, such as fuselage, wing and so on [1,2] due to its excellent properties, such as lightweight, high specific strength, good corrosion and fatigue resistance [3-5]. However, fire is one of the major security threats in its application. In July 2013, a Boeing 787 airliner caught fire at Heathrow airport in London because of the failure of ELT device close the tail of the fuselage, which led to the skin and frame of carbon fiber epoxy composite fuselage suffering serious thermal damage with significant resin loss and soot deposits [6].

In most cases, although the thermal conductivity of polymer matrix composites is lower than that of traditional metals, a series of physical and chemical changes occur in the environment of high temperature or exposure to flame directly, such as thermal softening, resin pyrolysis or even oxidization of fiber reinforced materials, resulting in the deformation and failure of composite structures. At the same time, toxic gases, smoke and fumes can be released during the process of the decomposition reaction of composite materials in fire, which will seriously threaten the safety of passengers [7]. As a result, some requirements of airworthiness concerning to the composites used in commercial airplane were established by FAA to ensure their safety in use. For instance, specific condition 25-348-SC [8] requires composite wing and fuel tank to endure an external fuel-fed pool fire for at least 5 minutes. Moreover, AC 20-107B [9] indicates that the flame retardant and fireresistant requirements of composite structures should be taken into account in the design of composite structures, as well as the exposure of composite materials to temperatures exceeding the maximum operating temperature. Therefore, it is essential to evaluate the thermal behavior of composites in fire and improve the fire resistance, especially for carbon epoxy laminates in aerospace 
industry. As a result, the numerical model for thermal response is always needed for engineering practice.

Many researchers have worked on predicting the thermal response of polymer composites decomposing at high temperatures using different mathematical models. Henderson et al. [10] proposed a one-dimensional thermal response model for composites with measured temperaturerelated thermo-physical parameters and reaction kinetic parameters in consideration of matrix pyrolysis and gas diffusion in the thickness direction, in which the predicted temperature distribution of the glass fiber/phenolic resin composite under one-sided heating agreed well with the experimental results. Furthermore, by taking into account the thermochemical expansion [13] in the thickness direction of the material and the flow and accumulation of decomposition gases, the transient thermal model was improved by Henderson and Wiecek [11,12]. Based on that model, Mike and Vizzini [14] established a three-dimensional thermal model of composites in consideration of the accumulation of material energy and anisotropic heat transfer for carbon fiber/epoxy resin composite exposed to heat flux $17.6 \mathrm{~kW} / \mathrm{m}^{2}$. Florio et al. [15] established a thermal model of ablative glass-filled composites with regard to matrix decomposition, expansion, and the heat exchange caused by the thermal imbalance between the decomposition gas and the solid material. Mouritz et al. [16] reviewed the research progress of structural response modeling of polymer composites under fire, and summarized the analytical models of thermal, chemical, physical and failure processes affecting the structural response of composites in fire. Steven [17] presented a framework for the response modeling of composites applied in combined mechanical loading and fire conditions, focusing on the response of composites prior to the decomposition temperature.

With the rapid development of modern design and analysis tools, commercial finite element software is used more and more widely to simulate the thermal response of composite materials in fire. Shi et al. $[18,19]$ predicted the thermomechanical behavior of a silica/phenolic composite, and investigated spatially dependent temperature and pore pressure, displacement ,and stress contours using COMSOL-Multiphysics commercial finite element software for the coupled temperaturediffusion-deformation problem, and proposed a model including the surface ablation module and volumetric ablation module to predict the ablation behavior of SiFRP composites. Zhang [20] exploited a three-dimensional model using ABAQUS commercial software, which included the influence of orthotropic viscoelasticity and pyrolysis to predict the thermomechanical behavior and compression failure of polymer-based composites subjected to compression and thermal loading. Rizk et al. [21] developed a three-dimensional thermal model for sandwich panels with glass/polyester skins and balsa core, defining the thermal behavior of materials using the UMATHT subroutine, in order to predict the evolution of the temperature gradient across a sandwich composite structure exposed to fire. LUO et al. [22-25] established a thermomechanical damage model and developed a finite element method using UMATHT and UMAT in ABAQUS, in order to solve the thermal and mechanical equations for glass-phenolic composite materials subject to high temperature and thermal radiative environments in consideration of the carbonization of sandwich composites, the decomposition of resins, the reduction of elastic modulus, and the delamination of panels and cores. Juhyeong Lee et al. [26] performed nonlinear finite element simulations to characterize lightning-induced thermal damage in AS4/3506 carbon/epoxy composites with metallic and nonmetallic protection layers, in which matrix thermal decomposition in composites subjected to $40 \mathrm{kA}$ peak currents were estimated using ABAQUS. Pauline T et al. [27-29] developed a three dimensional thermochemical model using SAMCEF software to predict the temperature profile, the mass loss and the decomposition front of a carbon-reinforced epoxy composite laminate (T700/M21 composite) exposed to fire. However, the process of charring and the characterization and regularity of the decomposition of carbon epoxy laminates exposed to fire is yet to be discussed and summarized.

In the present study, a transient thermal response finite element model of a carbon epoxy composite exposed to fire in consideration of anisotropic heat transfer, polymer decomposition and pyrolysis gas convection is established based on user subroutine of the finite element code ABAQUS 
in order to demonstrate the process of decomposition comprehensively. Firstly, heat transfer equation, decomposition rate equation, and continuity equation are applied to describe the thermal response of carbon epoxy composite exposed to fire, and are implemented in a finite element code using the user subroutine to define a material's thermal behavior (UMATHT). Secondly, The FE model of carbon fiber/epoxy composite laminates exposed to heat flux on one-side was established using the thermophysical parameters of material and boundary condition given in reference [28]. The temperature profiles are computed in order to prove the validity of the model by comparing the predicted results and the experimental data [29]. Lastly, the decomposition degree and the rate of decomposition of carbon epoxy composite are calculated by implementation of the updating of density using the user subroutine to redefine field variables (USDFLD) at any time, which can play an important role in gaining thorough insight into the thermal behavior, and summarizing the characterization and regularity of the decomposition of carbon epoxy laminates exposed to fire.

\section{Theoretical Model}

\subsection{Three-Dimensional Heat Transfer}

The heat transfer equation for composites when the gas flows in one direction is as follows Eq. (1), according to the following assumptions [10]:

1. There is no accumulation of decomposition gases in the solid material;

2. No thermo-chemical expansion of volume;

3. Thermal equilibrium between the decomposition gas and the solid material.

$$
\frac{\partial}{\partial t}\left(\rho h_{s}\right)-\nabla \cdot\left(k_{1} \frac{\partial T}{\partial x} \mathbf{i}+k_{2} \frac{\partial T}{\partial y} \mathbf{j}+k_{3} \frac{\partial T}{\partial z} \mathbf{k}\right)+\frac{\partial}{\partial z}\left(\dot{m}_{g}^{\prime} h_{g}\right)+Q \frac{\partial \rho}{\partial t}=0
$$

where $k_{i}(i=1,2,3)$ are thermal conductivities of composites in three different directions; $T, t$, $\rho, \dot{m}_{g}^{\prime}$ are temperature, time, solid density, mass flux of gases, respectively; $C_{p}, C_{p g}$ are solid specific heat, specific heat of gases generated from decomposition of resin, respectively; $h_{s}=\int_{T_{0}}^{T} C_{p} \mathrm{~d} T, \quad h_{g}=\int_{T_{0}}^{T} C_{p g} \mathrm{~d} T$ are solid enthalpy, enthalpy of gases, respectively; $Q$ is decomposition heat. The first term indicates the rate of internal energy change per unit volume. The second term shows the conduction flux. The thermal conductivity in the three mutually perpendicular directions, $k_{i}(i=1,2,3)$, contained in this term is a function of both temperature and the stage of decomposition of the material. The convection of energy resulting from the gaseous products flowing back through the char structure is given by the third term. The rate of heat generation or consumption resulting from the decomposition is represented by the last term. Definitely, the rate of introduction of this energy is affected by the rate of decomposition. If the decomposition process is endothermic, the heat of decomposition is negative; otherwise the heat of decomposition is positive. According to the description in [26], the decomposition reaction of the epoxy resin herein is endothermic.

\subsection{Modeling Decomposition}

The Arrhenius equation can draw the influence of temperature on the rate of decomposition reaction [30]. In this paper, only consider pyrolysis of resin, which is given by:

$$
\frac{\partial \rho}{\partial t}=-A\left(\rho_{v}-\rho_{d}\right)\left[\frac{\rho-\rho_{d}}{\rho_{v}-\rho_{d}}\right]^{n} \cdot \mathrm{e}^{-E / \mathrm{R} T}
$$

where $\rho, \rho_{v}, \rho_{d}$ are the instantaneous density, the virgin density, and the decomposed density, respectively; $\mathrm{R}=8.314(\mathrm{~J} / \mathrm{gmol} \cdot \mathrm{K})$ is universal gas constant. $A$ is rate constant, $E$ is activation energy, and $n$ is the order of pyrolysis reaction. These parameters are essential to describe the pyrolysis 
process. The Arrhenius parameters $A, n$, and $E$ can be obtained by using thermos-gravimetric analysis (TGA) tests.

If ignore the accumulation of gases, and consider only flows in the thickness direction, the conservation of mass represents:

$$
\frac{\partial \dot{m}_{g}^{\prime}}{\partial z}=-\frac{\partial \rho}{\partial t}
$$

\subsection{Thermal Properties at Different Material States}

Temperature and the decomposition state of the material influence thermal conductivity and specific heat capacity. The materials have different thermal properties in the three states of the material (original, decomposing and decomposed). The thermal properties in the original state and in the decomposed state can be determined by thermal tests, such as DSC and LFA. The mixing rule [30] can calculate the thermal properties in the decomposing state, given as follows:

$$
\begin{gathered}
F=\left(\rho-\rho_{d}\right) /\left(\rho_{v}-\rho_{d}\right) ; \\
k_{i}=F k_{v i}+(1-F) k_{d i}(i=1,2,3) ; \\
C=F C_{v}+(1-F) C_{d},
\end{gathered}
$$

where $k_{v i}, k_{d i}(i=1,2,3)$ are thermal conductivities of virgin and decomposed material in three coordinate directions. $C_{v}, C_{d}$ are specific heat capacities at virgin and decomposed states. $F$ is residual weight fraction of material to original material, while decomposition degree equals one minus $F$.

\subsection{Thermal Boundary Conditions}

For the purpose of numerically reproducing the experimental setup, a thermal flux has been applied as boundary condition to the heated surface, as shown in Eq. (7):

$$
q_{S, 0}^{\prime \prime}=\left(q_{\mathrm{rad}}^{\prime \prime}-\varepsilon_{S} \sigma T_{S}^{4}\right)+h_{\mathrm{conv}}\left(T_{\infty}-T_{S}\right)
$$

The boundary condition corresponded to the unexposed surface of the material is shown in the Eq. (8):

$$
q_{S, L}^{\prime \prime}=h_{\text {rear }}\left(T_{\infty}-T_{\text {rear }}\right)+\sigma \varepsilon_{S}\left(T_{\infty}^{4}-T_{\text {rear }}^{4}\right)
$$

Eq. (7) and Eq. (8) have considered the radiation and convective heat fluxes towards the environment. In the boundary equations above, $q_{\text {rad }}^{\prime \prime}$ represents the radiant heat flux. $\varepsilon_{S}$ is emissivity, which was set to be 0.99 and 0.95 for the exposed surface and the rear surface according to the literature[31], respectively. $\sigma$ is Stefan-Boltzmann Constant. $T_{S}$ is the temperature of the exposed surface. $T_{\infty}$ is assumed constant as the temperature of ambience and equal to $295 \mathrm{~K}$ according to the literature[27]. $T_{\text {rear }}$ is the temperature of the unexposed surface. $h_{\text {conv }}$ is the convection heat flux coefficient of the exposed surface, and estimated to be $80 \mathrm{~W} /\left(\mathrm{m}^{2} \mathrm{~K}\right)$ according to the literature [31]. $h_{\text {rear }}$ is the convection heat flux coefficient of the unexposed surface, and assumed to be $25 \mathrm{~W} /\left(\mathrm{m}^{2} \mathrm{~K}\right)$ according to the literature [32].

\section{Finite Element Implementation}

\subsection{Experiemental description and Finite Element Model}


According to the experiment information and thermal parameters presented in the literature $[27,29]$, the finite element model and computation procedure were developed via ABAQUS code. A carbon/epoxy laminate, whose size is $150 \mathrm{~mm} \times 150 \mathrm{~mm} \times 4 \mathrm{~mm}$, has been manufactured using unidirectional (UD) prepregs, which is often used in aircraft for primary and secondary structures, with a stacking of [0]s (UD). The fibres and resin used in these prepregs are T700GC carbon fibres and M21 epoxy resin from Toray industry and Hexcel industry respectively. The properties of T700/M21 are shown in Table 1.

According to the description in the standard of ISO2685:1998(E), the coupon of T700/M21 is impacted by the calibrated propane flame providing the one-sided heat flux of $116 \mathrm{~kW} / \mathrm{m}^{2}$ for $5 \mathrm{~min}$. Although this is different from the cone calorimeter test[33,34], the stability of fire was demonstrated by Pauline [27]. During the test, the specimen is placed in a vertical orientation and at a distance of $75 \mathrm{~mm}$ from the burner nose. Experimental setup is shown in Figure 1. The. It should be noted that the area of the impacted region in the experiment on the exposed surface is $100 \mathrm{~mm} \times 100 \mathrm{~mm}$, while the rest of the exposed surface is covered by a heat shield, which is a heat insulated region, as shown in Fig 2a. This insulated shield has good mechanical characteristics and is thermally stable. For the measurement of the temperature, three K-type thermocouples with a diameter of $0.25 \mathrm{~mm}$ are embedded at the center of the plane at $z=1,2$, and $3 \mathrm{~mm}$ from the exposed surface, and another $\mathrm{K}$ type thermocouple is attached to the center of the back face, as shown in Figure $2 b$.

The FE model was established using DC3D8 units, and the total number of elements is 14,400. The direction of the fiber is defined to $x$ direction, and the thickness direction of the coupon is defined to $\mathrm{z}$ direction. A nonuniform heat flux was imposed on the impacted region of the surface as shown in Figure 3, which was determined according to the heat flux mapping in the test [27]. And it was achieved by subroutine, using a double-ellipse function to represent the variation of heat flux from the centre to the edge gradually and the asymmetry caused by buoyancy.

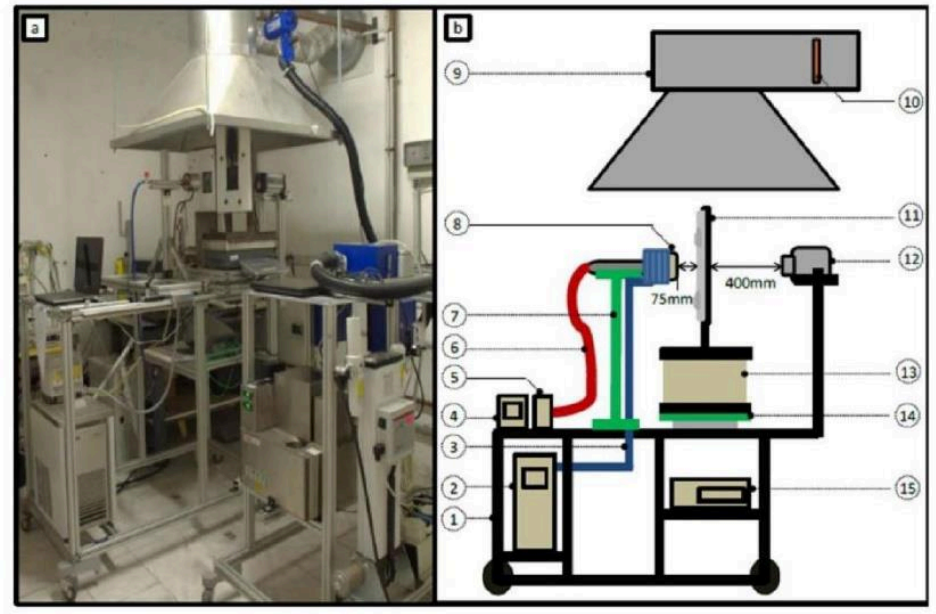

FIG.1. Experimental setup [29]
(1) Test bench frame, (2) Cooling thermostat, (3) Copper coil cooler, (4) Propane thermocontroller, (5) Propane flowmeter, (6) Propane gas line, (7) Burner support, (8) Propane flame burner, (9) Hood, (10) Ring sampler, (11) Coupon support, (12) Infrared (IR) camera, (13) Precision balance, (14) Balance support, (15) Data acquisition device 


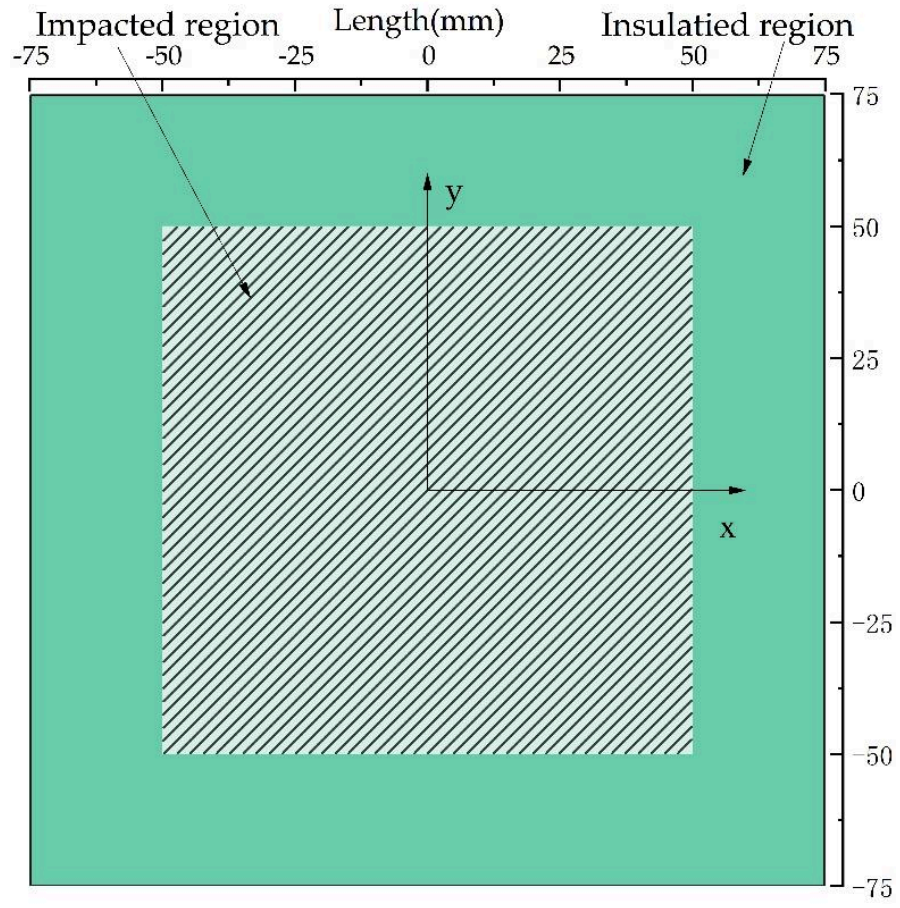

(a)

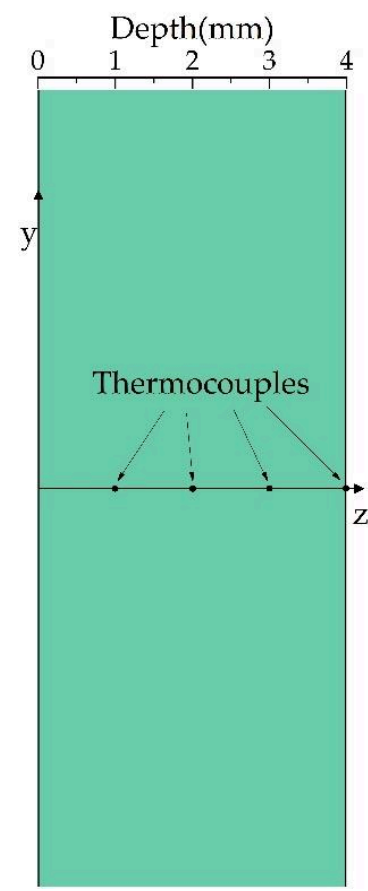

(b)

FIG.2. (a) Division of regions on the heated surface; (b) Distribution of thermocouples in thickness direction

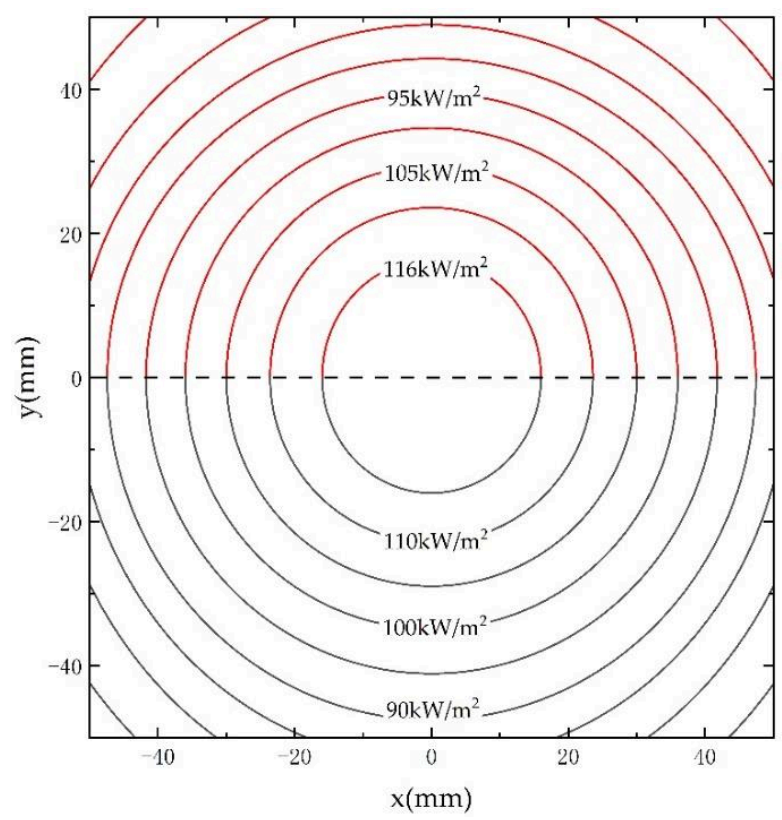

FIG.3. The asymmetrical distribution of heat flux on the impacted region

\subsection{User Subroutine Development}

The following items must be defined and updated in the subroutine UMATHT: the heat flux vector $\mathbf{f}$ and its variation with respect to temperature and spatial gradients of temperature; internal energy per unit mass $U$ and its variation with temperature and spatial gradients of temperature; the solution-dependent state variables at the end of the increment must be updated to their values. The components of the heat flux and spatial gradients in user subroutine UMATHT are in directions that depend on the use of local orientations. The decomposition equation is implemented into heat transfer UMATHT using finite forward difference to update the remaining density of material. 
Table 1. Material properties for T700/M21 composites [28]

\begin{tabular}{|c|c|}
\hline Parameter & Value \\
\hline Virgin Density $/ \mathrm{kg} \cdot \mathrm{m}^{-3}$ & 1575 \\
\hline Char Density $/ \mathrm{kg} \cdot \mathrm{m}^{-3}$ & 1165 \\
\hline Virgin Thermal Conductivity in thickness $/ \mathrm{W} \cdot \mathrm{m}^{-1} \cdot \mathrm{K}^{-1}$ & $0.61391+1.1113 \times 10^{-3} \mathrm{~T}$ \\
\hline Virgin Thermal Conductivity in plane $/ \mathrm{W} \cdot \mathrm{m}^{-1} \cdot \mathrm{K}^{-1}$ & $7.4675 \times 10^{-3} T+2.7811$ \\
\hline Char Thermal Conductivity in thickness $/ \mathrm{W} \cdot \mathrm{m}^{-1} \cdot \mathrm{K}^{-1}$ & $\begin{array}{c}0.12317+3.7323 \times 10^{-4} \mathrm{~T}+1.1841 \times 10^{-9} \mathrm{~T}^{3}- \\
6.6846 \times 10^{-7} \mathrm{~T}^{2}\end{array}$ \\
\hline Char Thermal Conductivity in plane $/ \mathrm{W} \cdot \mathrm{m}^{-1} \cdot \mathrm{K}^{-1}$ & $1.4421+4.0682 \times 10^{-3} T-2.2242 \times 10^{-6} T^{2}$ \\
\hline Virgin Specific Heat/ $\mathrm{J} \cdot \mathrm{kg}^{-1} \cdot \mathrm{K}^{-1}$ & $687.31+2.8773 T$ \\
\hline Char Specific Heat $/ \mathrm{J} \cdot \mathrm{kg}^{-1} \cdot \mathrm{K}^{-1}$ & $662.53+2.599 \mathrm{~T}+5.132 \times 10^{-7} \mathrm{~T}^{3}-2.0761 \times 10^{-3} \mathrm{~T}^{2}$ \\
\hline Specific Heat of Gases $/ \mathrm{J} \cdot \mathrm{kg}^{-1} \cdot \mathrm{K}^{-1}$ & $\begin{array}{c}1256.6+1.0610 T+3.5977 \times 10^{-7} T^{3}-9.2485 \times 10^{-4} \\
T^{2}\end{array}$ \\
\hline Activation Energy $E / \mathrm{J} \cdot \mathrm{mol}^{-1}$ & $181.73 \times 10^{3}$ \\
\hline Order of Reaction $n$ & 1.344 \\
\hline Pre-exponential Factor $A / 1 \cdot \mathrm{s}^{-1}$ & $3.15 \times 10^{11}$ \\
\hline Heat of Decomposition/ $\mathrm{J} \cdot \mathrm{kg}^{-1}$ & $107.32 \times 10^{3}$ \\
\hline
\end{tabular}

Eq. (1) is recast by expanding the first term using differentiation rules and combining the heat convection term using Eq. (3), yielding the final form of heat transfer equation for finite element implementation:

$$
\rho C_{p} \frac{\partial T}{\partial t}-\nabla \cdot\left(k_{1} \frac{\partial T}{\partial x} \mathbf{i}+k_{2} \frac{\partial T}{\partial y} \mathbf{j}+k_{3} \frac{\partial T}{\partial z} \mathbf{k}\right)+\dot{m}_{g}^{\prime} C_{p g} \frac{\partial T}{\partial z}+\left(h_{s}+Q-h_{g}\right) \frac{\partial \rho}{\partial t}=0
$$

The basic energy balance is:

$$
\int_{V} \rho \dot{U} \mathrm{~d} V=\int_{S} q \mathrm{~d} S+\int_{V} r \mathrm{~d} V
$$

where $V$ is the volume of the solid material with surface area $S, \rho$ is the density of the material, $\dot{U}$ is the material time rate of the internal energy, $q$ is the heat flux per unit area of the body flowing into the body, and $r$ is the heat supplied externally into the body per unit volume.

A heat flux vector $\mathbf{f}$ is defined such that:

$$
q=-\mathbf{f} \cdot \mathbf{n}
$$

where $\mathbf{n}$ is the unit outward normal to the surface $S$. Introducing the above relation into the energy balance equation and using the divergence theorem, as the following relation is obtained:

$$
\int_{V} \rho \dot{U} \mathrm{~d} V=-\int_{V} \frac{\partial}{\partial \mathbf{x}} \cdot \mathbf{f} \mathrm{d} V+\int_{V} r \mathrm{~d} V
$$

The internal energy $U$, the heat flux vector $\mathbf{f}$, and their variation with respect to temperature and to spatial gradients of temperature are the interface variables provided by UMATHT for numerical implementation [35]. UMATHT must define these variables and update their values at the end of the increment.

Combining Eq. (9) with Eq. (12), yielding the time rate of the internal thermal energy and the heat flux vector: 


$$
\begin{gathered}
\dot{U}=C_{p} \frac{\partial T}{\partial t}+\frac{1}{\rho}\left(Q+h_{s}-h_{g}\right) \frac{\partial \rho}{\partial t}+\frac{C_{p g}}{\rho} \int_{l}^{z} \frac{\partial \rho}{\partial t} \mathrm{~d} z \frac{\partial T}{\partial z} \\
\mathbf{f}=-k_{1} \frac{\partial T}{\partial x} \mathbf{i}-k_{2} \frac{\partial T}{\partial y} \mathbf{j}-k_{3} \frac{\partial T}{\partial z} \mathbf{k}
\end{gathered}
$$

Introducing the finite difference approximation, the incremental form of Eq. (13) is given by:

$$
\Delta U=C_{p} \Delta T+\left(Q+h_{s}-h_{g}\right) \frac{\Delta \rho}{\rho}+\frac{C_{p g}}{\rho} \int_{l}^{z} \frac{\partial \rho}{\partial t} \mathrm{~d} z \frac{\partial T}{\partial z} \Delta t
$$

Eq. (15) is used to update the internal energy at the end of time increment $U(t+\Delta t)$ using the energy at the beginning of the time increment $U(t)$.

$$
U(t+\Delta t)=U(t)+\Delta U
$$

When the internal energy is a function of time, temperature, remaining density and its partial derivative with respect to special coordinates, the derivative of the total internal energy as a function of time is given by:

$$
\frac{\mathrm{d} U}{\mathrm{~d} t}=\frac{\partial U}{\partial t}+\frac{\partial U}{\partial T} \frac{\mathrm{d} T}{\mathrm{~d} t}+\frac{\partial U}{\partial\left(\partial T / \partial x_{i}\right)} \frac{\mathrm{d}\left(\frac{\partial T}{\partial x_{i}}\right)}{\mathrm{d} t}+\frac{\partial U}{\partial \rho} \frac{\mathrm{d} \rho}{\mathrm{d} t}+\frac{\partial U}{\partial\left(\partial \rho / \partial x_{i}\right)} \frac{\mathrm{d}\left(\frac{\partial \rho}{\partial x_{i}}\right)}{\mathrm{d} t}
$$

Compare terms in Eq. (17) and Eq. (13), yielding:

$$
\begin{gathered}
\frac{\partial U}{\partial T}=C_{p} \\
\frac{\partial U}{\partial\left(\partial T / \partial x_{i}\right)}=0, \quad i=1,2,3 \quad x_{1}=x, x_{2}=y, x_{3}=z
\end{gathered}
$$

Based on Eq. (14), the partial derivative of heat flux vector with respect to temperature and temperature spacial gradient can be expressed by:

$$
\begin{gathered}
\frac{\partial \mathbf{f}}{\partial T}=-\frac{\partial T}{\partial x} \frac{\partial k_{1}}{\partial T} \mathbf{i}-\frac{\partial T}{\partial y} \frac{\partial k_{2}}{\partial T} \mathbf{j}-\frac{\partial T}{\partial z} \frac{\partial k_{3}}{\partial T} \mathbf{k} \\
\frac{\partial \mathbf{f}}{\partial\left(\partial T / \partial x_{i}\right)}=\left[\begin{array}{ccc}
-k_{1} & 0 & 0 \\
0 & -k_{2} & 0 \\
0 & 0 & -k_{3}
\end{array}\right], i=1,2,3 \quad x_{1}=x, x_{2}=y, x_{3}=z
\end{gathered}
$$

The Figure 4 shows the flow chart of the calculation. When the resin matrix in the composite material does not decompose, the decomposition degree is 0 ; when the resin matrix is completely carbonized, the decomposition degree is 1. In the subroutine, the decomposition degree and decomposition rate of the material were obtained by kinetic equation, and stored in the state variable array STATEV(), the state variable STATEV(1) was updated and passed to the subroutine USDFLD to obtain the decomposition rate. The internal thermal energy of the material and the conducted heat flux were calculated by the UMATHT module. And the changed heat was transferred to the ABAQUS thermal analysis module to obtain an updated temperature field and decomposition rate field, which was continuously cycled and iterated by superimposing the time increment, until the end of the analysis step to get the final temperature field, decomposition rate field, and so on. 


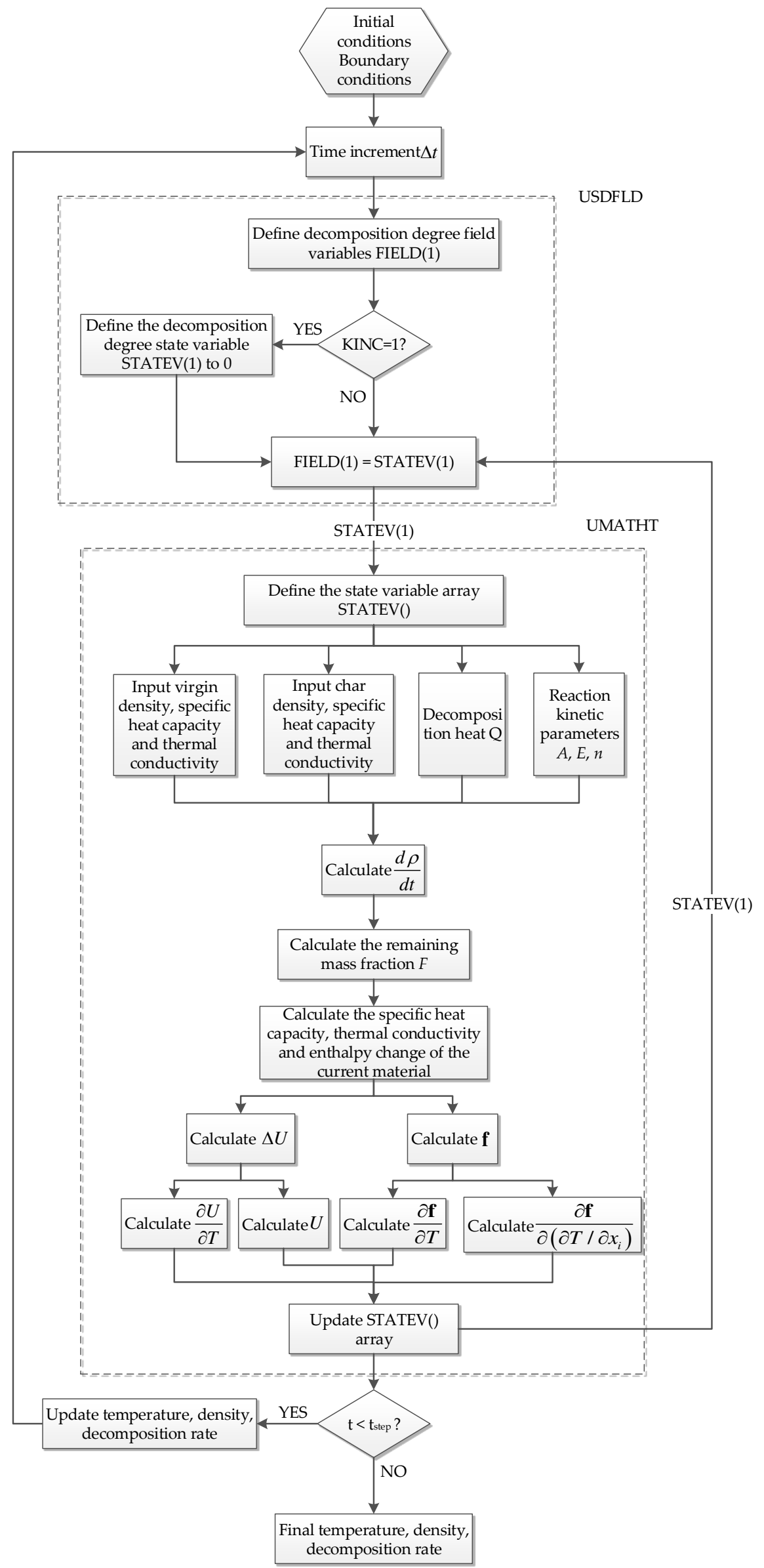

FIG.4. Flow chart of the thermal response calculation 


\section{Results and discussion}

\subsection{Field of Temperature}

Figure 5 shows that a comparison between the computed and measured temperature profiles of T700/M21 composites at the center of plane at $z=1,2,3$ and $4 \mathrm{~mm}$. It suggests that at the beginning of test there is an obvious temperature rise at all four depths. This is because when the coupon whose thickness is only $4 \mathrm{~mm}$ is exposed to the heat flux of $116 \mathrm{~kW} / \mathrm{m}^{2}$, heat can be rapidly transmitted to the back. Latterly, the rates of temperature rise at $z=1$ and $2 \mathrm{~mm}$ begin to decrease, the temperature rises slowly, while the temperatures at $z=3$ and $4 \mathrm{~mm}$ are almost steady, which has been in a state of heat equilibrium. The calculated values of temperature at $z=1$, and $2 \mathrm{~mm}$ are in good agreement with the experimental data due to the high accuracy of the inputs of virgin material and the appropriate initial boundary, as indicated by Pauline Tranchard [29]. But that at $3 \mathrm{~mm}$ and $4 \mathrm{~mm}$ are overestimated compared with the experimental ones after 50s, which is similar to the predictions by Pauline Tranchard. The reason may be that the heat exchanging between the laminates and gas released from the decomposition and the interaction between the materials surface and out-gassing were not taken into account. Additionally, it was indicated that there was a lack of accuracy of the temperature measurement [29].

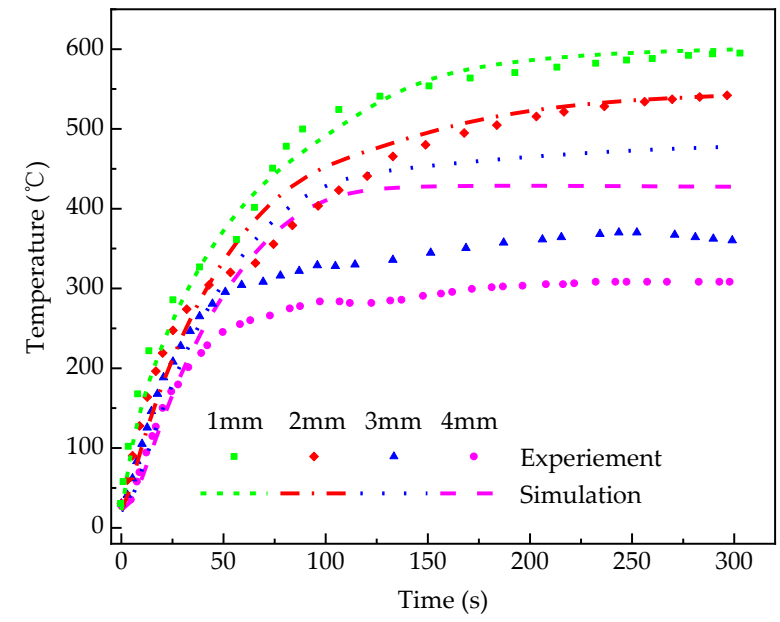

FIG.5. Comparison of the computed and measured results of the temperature profile of T700/M21

Figure $6 \mathrm{a}$ and $6 \mathrm{~b}$ show the temperature contours of FE model at $100 \mathrm{~s}$ and $300 \mathrm{~s}$, respectively. At $100 \mathrm{~s}$, the temperature of most impacted region on the exposed surface reaches the pyrolysis temperature of T700/M21, which is higher than that of insulated region obviously. Since heat can be transmitted from the impacted region to the insulated region in the plane direction of the coupon, the region where temperature exceeds the pyrolysis temperature enlarges from the center towards the periphery gradually. It should be indicated that the coupon is stacked with unidirectional prepreg by unidirectional layup, so the thermal conductivity in the $\mathrm{x}$ direction is higher than that in the $\mathrm{y}$ direction, leading to the discrepancy of temperature along the $\mathrm{x}$ and $\mathrm{y}$ directions, namely an asymmetric distribution of temperature. Therefore, in the insulated region, the area where the temperature changes obviously in the $x$ direction is larger than that in the $y$ direction. On the other hand, the heat is gradually transmitted from the exposed surface to the back in the thickness direction, and the temperature exhibits a gradient distribution. The maximum temperature increases with heating time, up to $651^{\circ} \mathrm{C}$ at $300 \mathrm{~s}$. 


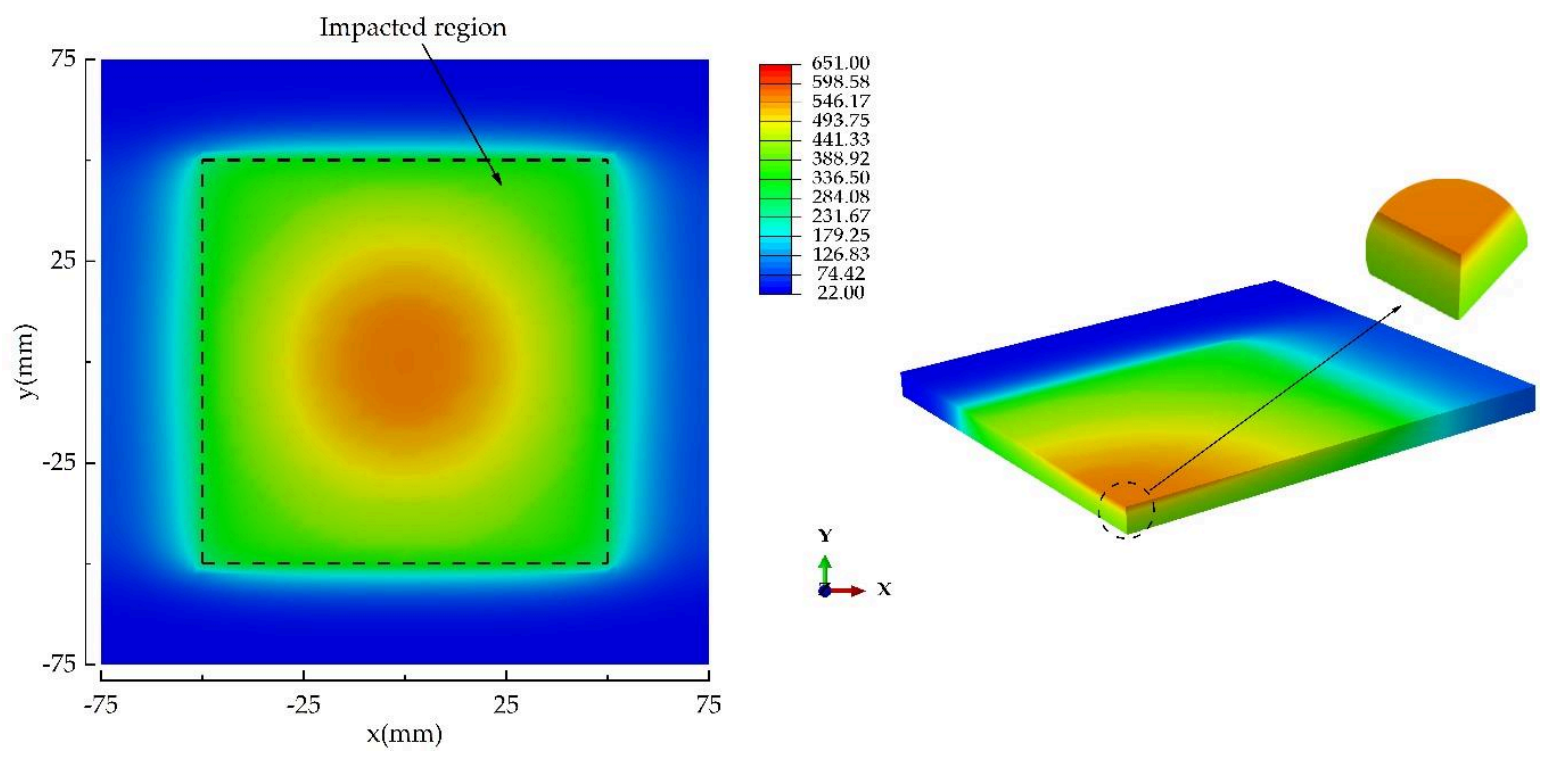

(a) $100 \mathrm{~s}$

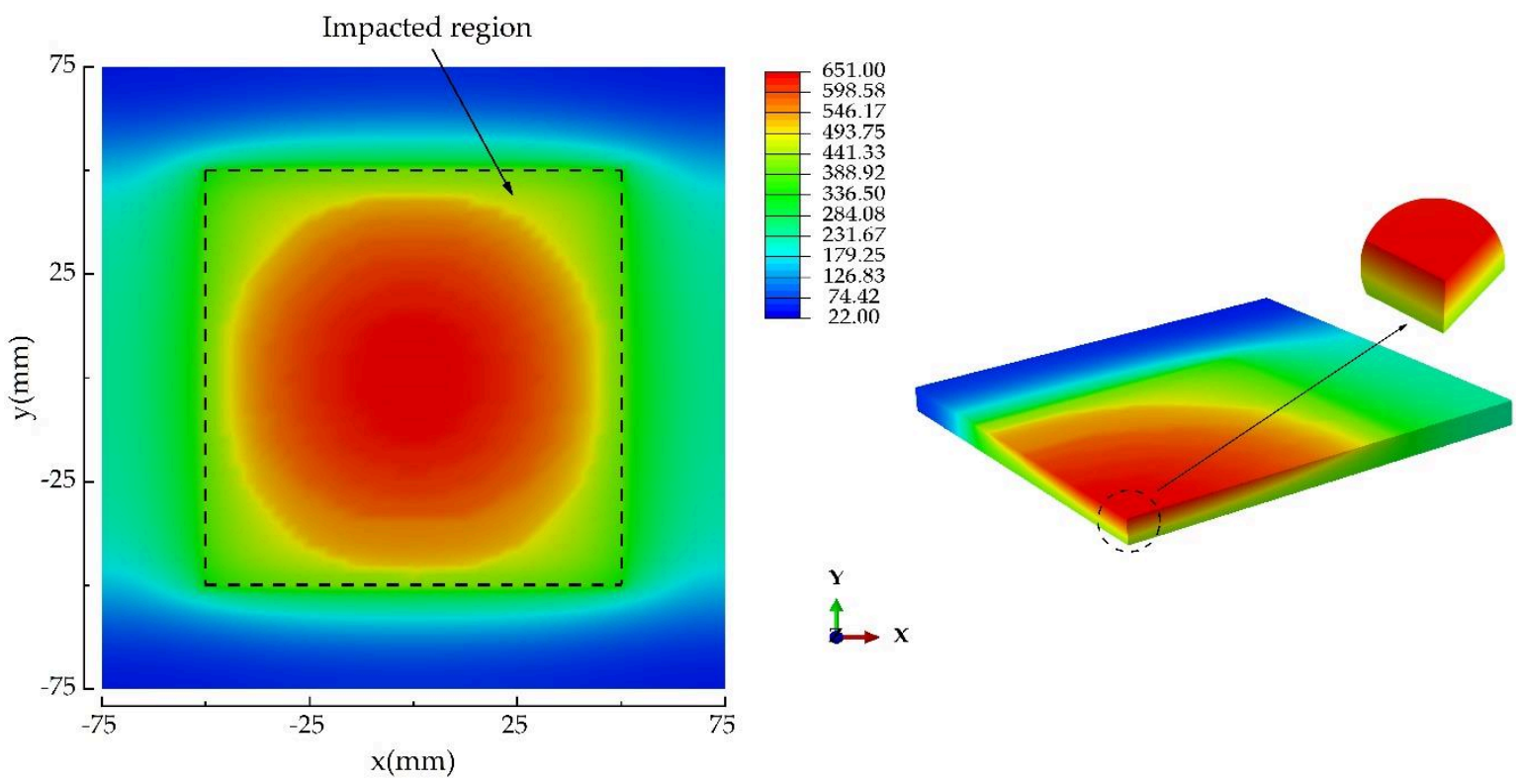

(b) $300 \mathrm{~s}$

FIG.6. Temperature contours of 1/4 FE model at different moments

Figure $7 \mathrm{a}$ and $7 \mathrm{~b}$ show that the temperature distribution at different times on the symmetric line of $x$ and $y$ direction of the exposed surface respectively, wherein the range of $-50 \mathrm{~mm} \sim+50 \mathrm{~mm}$ belongs to the impacted region, and that of $\pm 50 \sim \pm 75 \mathrm{~mm}$ belongs to the insulated region. At $20 \mathrm{~s}$, an obvious temperature rise of the impacted region on the exposed surface has occurred relative to the insulated region, and the temperature at the center is the highest. However, in the insulated region there is an obvious temperature gradient close to the boundary between two regions. Generally, the temperature in both regions are constantly rising with heating time, but that in the impacted region rises much more than the insulated one. The reason is that the temperature in the impacted region mainly depends on by the heat flux of external propane flame, but that for the insulated region is dominated by heat conduction from the impacted region to the insulated one. Furthermore, the lower the temperature is, the smaller the thermal conductivity is. Consequently, the conducted heat is relatively less in the insulated region, namely the temperature change in the insulated region is smaller. In addition, the temperature rise along the $\mathrm{x}$ direction in the insulated region is higher than that along the $y$ direction, and the temperature gradient on the symmetric line in the $x$ direction is smaller than 
that in the $y$ direction. This is due to the difference of thermal conductivity in $\mathrm{x}$ and $\mathrm{y}$ direction. The temperature curve at $300 \mathrm{~s}$ in the y direction on the exposed surface is almost unchanged corresponding to that at $200 \mathrm{~s}$, but in the $\mathrm{x}$ direction the temperature change close to the edge of coupon is still remarkable due to the higher thermal conductivity.

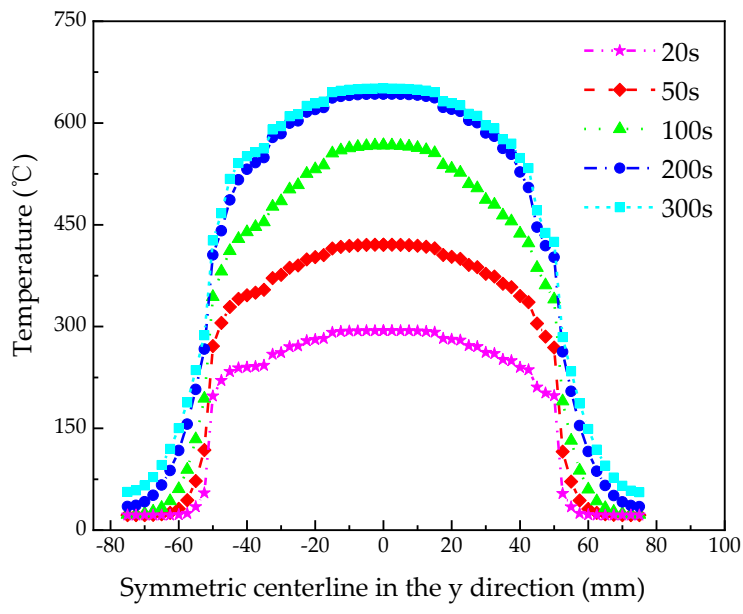

(a)

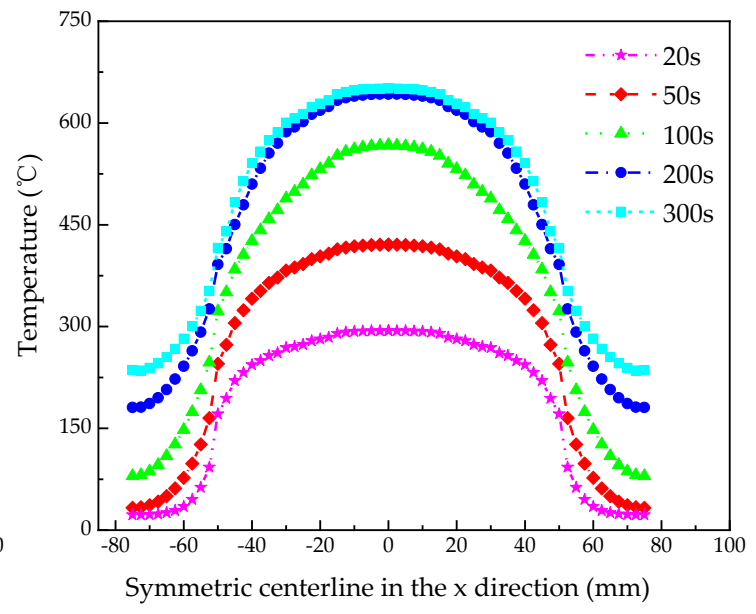

(b)

FIG.7. Temperature distribution along the symmetric line on the exposed surface

Figure 8 shows the rate of temperature rise at the center of the plane at $z=1,2,3$ and $4 \mathrm{~mm}$. They rise up rapidly first and then decreases, and finally approach zero, which corresponds to the slope of temperature profile in Figure 5. It suggests that the peaks of the rate of temperature rise at different depths are different. The deeper away from the exposed surface, the smaller the peak of the rate of temperature rise. Namely, the rates of temperature rise at $z=1,2,3$ and $4 \mathrm{~mm}$ reached their peak values of $16.61^{\circ} \mathrm{C} / \mathrm{s}, 9.25^{\circ} \mathrm{C} / \mathrm{s}, 7.68^{\circ} \mathrm{C} / \mathrm{s}$ and $7.33^{\circ} \mathrm{C} / \mathrm{s}$ at $2 \mathrm{~s}, 6 \mathrm{~s}, 13 \mathrm{~s}$, and $14 \mathrm{~s}$, respectively. After that, the rates of temperature rise at different depths gradually decrease with heating time. For this, the first reason is that the temperature rise leads to the enhancement of heat dissipation capacity of the coupon. The second is when the temperature reaches the pyrolysis temperature, the pyrolysis reaction occurs, which absorbs the heat to some extent. The last one is that the diffusion of pyrolysis gas takes the heat to the surface partly.

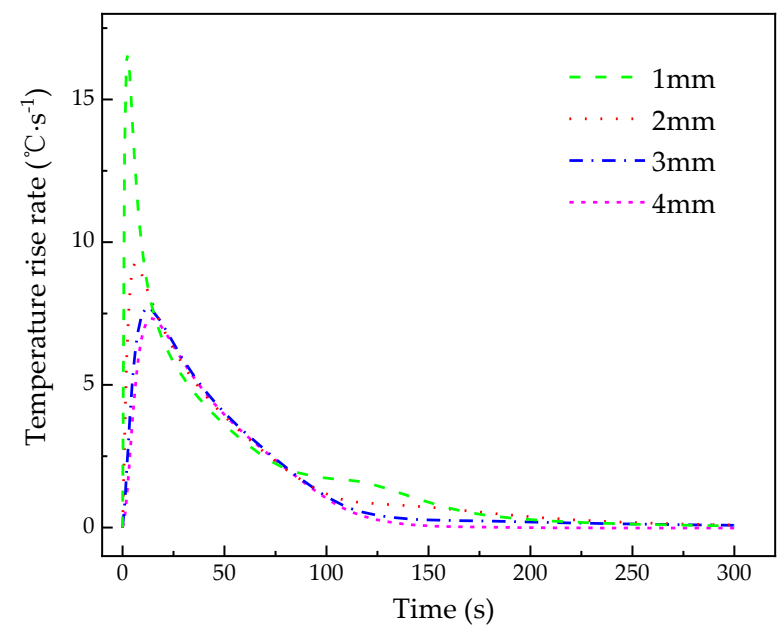

FIG.8. Rate of temperature rise of the center at different depths over time

\subsection{Density and decomposition degree}

Figure 9 shows the density of solid material with increasing heating time at the center of the plane at $z=1,2,3$ and $4 \mathrm{~mm}$. Firstly, according to Figure 5, the temperature at $z=1$ and $2 \mathrm{~mm}$ reaches the critical pyrolysis temperature at $54 \mathrm{~s}$ and $63 \mathrm{~s}$, respectively, and then the pyrolysis reaction occurs. And then, the discrepancy among the material densities at four depths increases with time, because 
pyrolysis reaction at different depths occurs in succession with time. The farther away from the exposed surface, the lower the degree of decomposition, so the higher the material density at any time. Finally, the material at $z=1$, and $2 \mathrm{~mm}$ become a state of fully charring, that is, the densities reach to that of the carbonized material at 139 s, 196 s, respectively. In contrast, although pyrolysis reaction at $z=4 \mathrm{~mm}$ also occurred, the material does not become a state of complete charring up to $300 \mathrm{~s}$, and the densities are just between the virgin and the char densities.

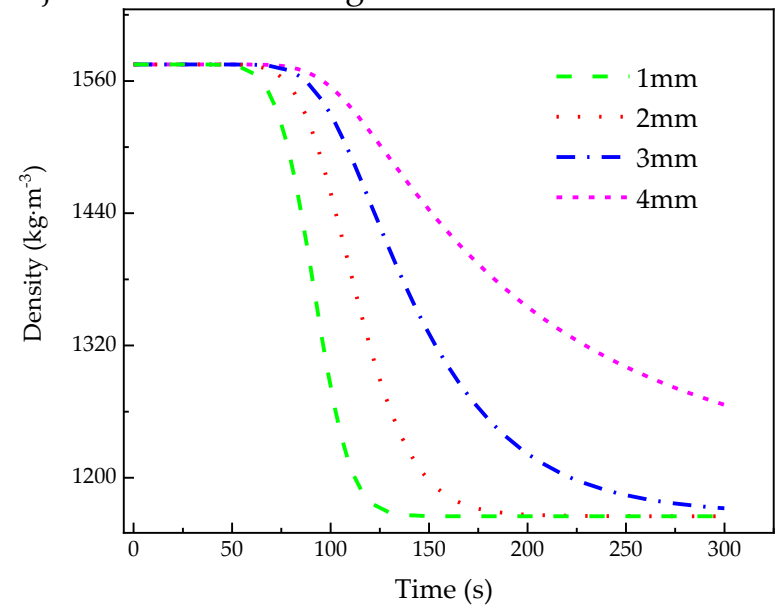

FIG.9. Density of the center at different depths over time

Figure 10a and 10b show contours of decomposition degree of FE model at $100 \mathrm{~s}$ and $300 \mathrm{~s}$ respectively, which is defined in section 2.3 , namely " $1-F$ ". The decomposition degree of 0 represents that the material density is the virgin density, and the decomposition degree of 1 represents that the material density is the char density. At $100 \mathrm{~s}$, the materials in the range from -20 to $20 \mathrm{~mm}$ has become the state of complete charring, and the density in this zone reduces to the char density, namely the decomposition degree is 1 . The fully carbonized area in the impacted region continues to enlarge with time towards the boundary between two regions, but the decomposition degree in the insulated region does not rise almost. Therefore, the area in which the pyrolysis reaction is in process shrinks with time. In addition, in the thickness direction the decomposition degree decreases with depth. This means that the decomposition front shifts from the exposed surface to the back. At $300 \mathrm{~s}$, most materials in the impacted region has become the fully charring state, and the border of the fully decomposed region is very close to the boundary between the impacted and insulated regions. The results shown in reference [29] also indicates that the density of the material in the impacted region reduces to the char density at the end of test. Therefore, it is considered that calculated results in this paper has a good consistency with the experimental results.

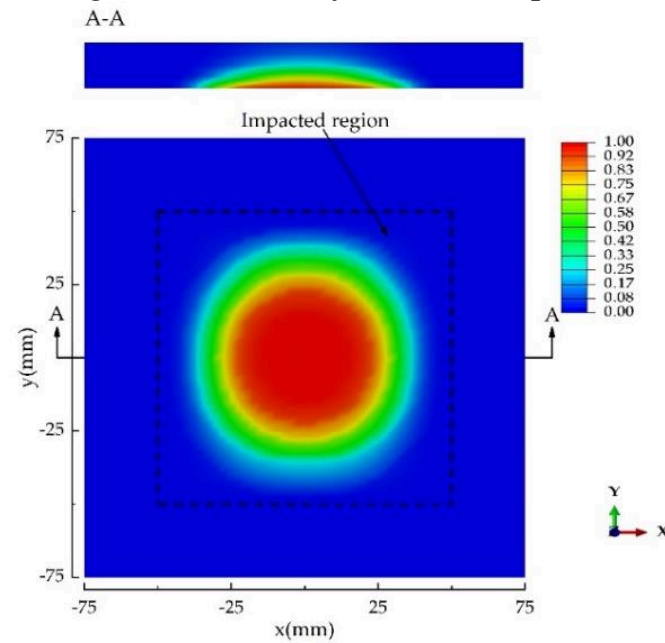

(a) $100 \mathrm{~s}$

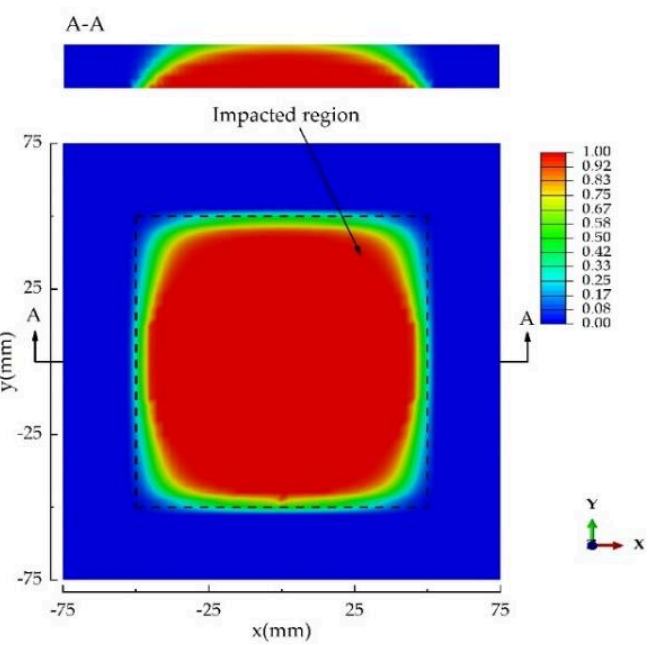

(b) $300 \mathrm{~s}$

FIG.10. Contours of decomposition degree at different times 
Figure 11a and 11b show the decomposition degree of T700/M21 along the symmetric line in $\mathrm{x}$ and y direction on the exposed surface at different moments respectively. Pyrolysis reaction has occurred in the impacted region at $50 \mathrm{~s}$. The maximum decomposition degree, which is located at the center of the exposed surface, is $3 \%$ at this time, while there is almost no decomposition in the insulated region. Then, the decomposition degree in the impacted region increases with time, namely the material density decreases to the char density. Specially, it is shown that there is a significant change of decomposition degree in the vicinity of $50 \mathrm{~mm}$. This is because the heat shield works well in preventing the material in insulated region from being impacted by the heat flux of external propane flame directly, and the critical pyrolysis temperature cannot be achieved just by the heat conduction of materials. Therefore, there is discrepancy of density of materials, namely difference of decomposition degree. This also can be implied from the results in Figure 7.

Figure 12 shows the decomposition degree of T700/M21 with temperature at the center of plane at $z=1,2,3$ and $4 \mathrm{~mm}$, which is similar to the typical TG curves of polymer composites. The materials at $z=1$ and $2 \mathrm{~mm}$ has decomposed completely at $522{ }^{\circ} \mathrm{C}$ and $501{ }^{\circ} \mathrm{C}$ respectively, but complete decomposition is not achieved at $z=3$ and $4 \mathrm{~mm}$ up to the end of test, where decomposition degrees are $98.2 \%$ and $75.2 \%$ at $300 \mathrm{~s}$, respectively. It is important to be noted that when the temperature at different depths reaches the same temperature, decomposition degrees of the materials are different. At any temperature, the closer to the exposed surface, the lower the decomposition degree. And when the same decomposition degree at different depths is achieved, the material temperature values are different. Namely, the farther away from the exposed surface, the lower the temperature. This is because when the same temperature or decomposition degree of material is achieved, the rates of temperature rise at different depths are different, while the pyrolysis reaction of epoxy resin is affected by the rate of temperature rise. Smaller the rate of temperature rise, more adequate the pyrolysis reaction of epoxy resin is. From another point of view, the higher the rate of temperature rise, the higher the temperature required for material pyrolysis [36].

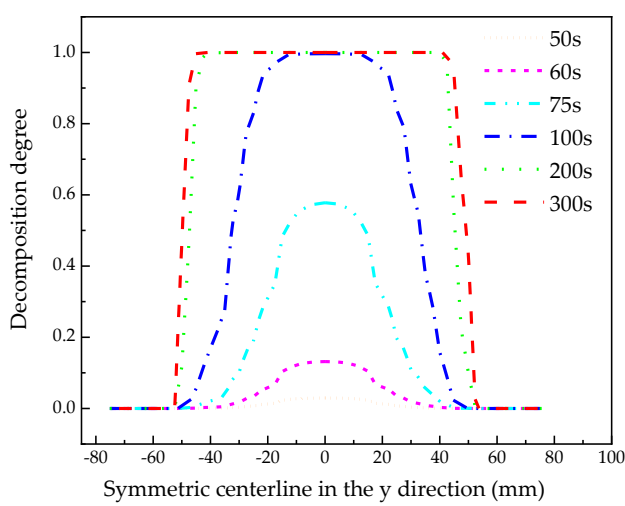

(a) $\mathrm{x}$ direction

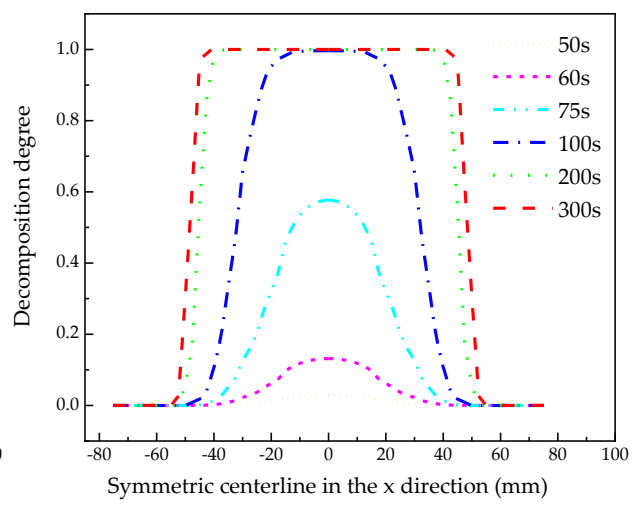

(b) y direction

FIG.11. Decomposition degree along symmetric line on the exposed surface at different heating moments 


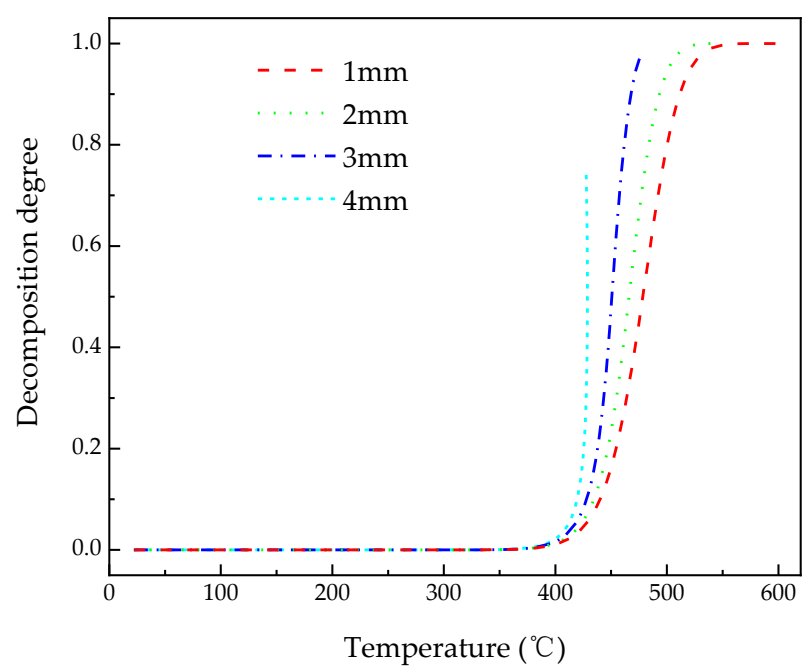

FIG.12. Decomposition degree with temperature at different depths

\subsection{Decomposition Rate}

Figure 13 shows the decomposition rates of T700/M21 composites with time at the center of the plane at $z=1,2,3$ and $4 \mathrm{~mm}$. The decomposition rate can represent the intensity of pyrolysis reaction as well as the rate of mass change of the material. The respective peaks of decomposition rate of the materials at $z=1,2,3$ and $4 \mathrm{~mm}$, which are achieved at $92 \mathrm{~s}, 108 \mathrm{~s}, 122 \mathrm{~s}, 129 \mathrm{~s}$ respectively, are $2.69 \% / \mathrm{s}, 1.76 \% / \mathrm{s}, 1.07 \% / \mathrm{s}$, and $0.59 \% / \mathrm{s}$. It suggests that the peak values of decomposition rate gradually decrease with depth, and the time to reach the peak of decomposition rate gradually is delayed with depth, too. This is due to the different rates of temperature rise at different depths.

Figure 14 shows the decomposition rate of T700/M21 composites with temperature at the center of the plane at $z=1,2,3$ and $4 \mathrm{~mm}$, which is similar to the typical DTG curves of polymer composites. The respective peaks of decomposition rate of the materials at $z=1,2,3$ and $4 \mathrm{~mm}$ are achieved at $477{ }^{\circ} \mathrm{C}, 461{ }^{\circ} \mathrm{C}, 443{ }^{\circ} \mathrm{C}, 425^{\circ} \mathrm{C}$. It suggests that the temperatures at which the material at different depths reach the peak of the decomposition rate are different, and the further away from the exposed surface, the lower the temperature at which the peak of the decomposition rate is reached. The reason is when the peaks of decomposition rate of material at different depths are achieved, the rates of temperature rise are different. The closer to the exposed surface, the higher the rate of temperature rise, which leads to the maximum decomposition rate of the composite to move toward the higher temperature. On the other hand, it is noted that the temperature range of pyrolysis reaction is widened with the rate of temperature rise, which is also indicated in reference [37].

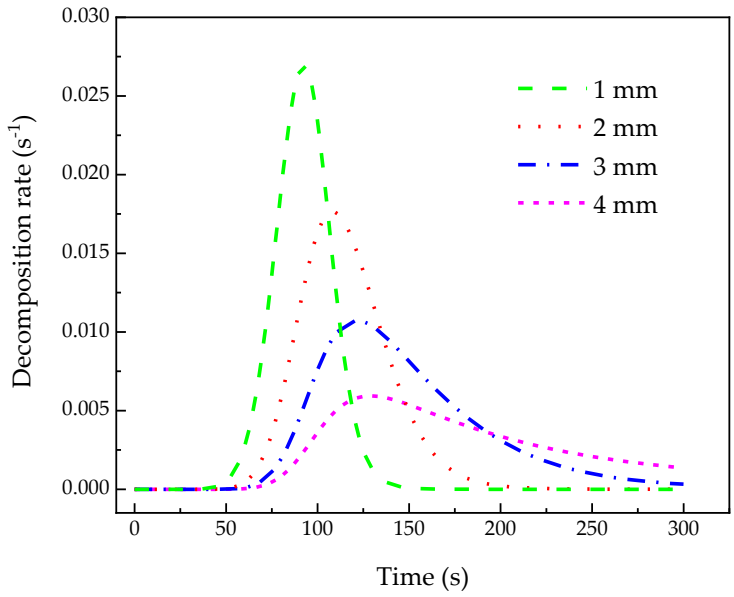

FIG.13. Decomposition rate over time at different depths

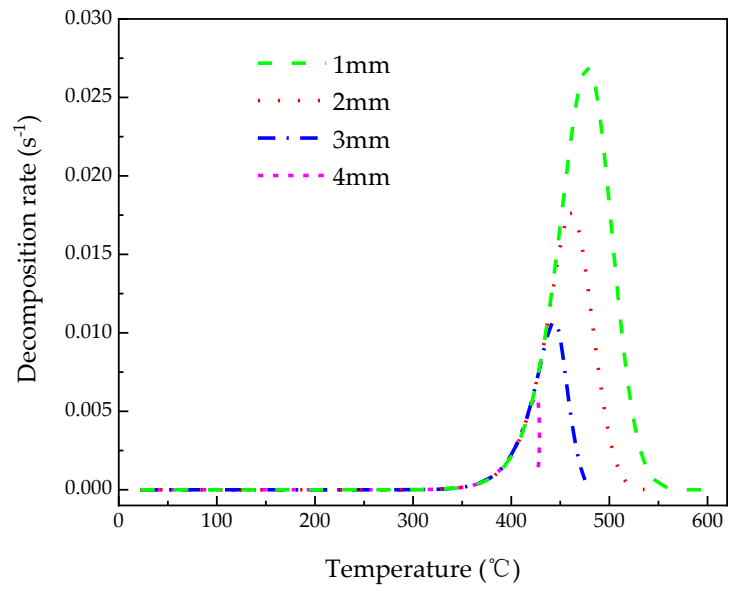

FIG.14. Decomposition rate with temperature at different depths 


\section{Conclusions}

In consideration of anisotropic heat transfer, polymer decomposition and gas diffusion, a transient three-dimensional FE model for carbon fiber/epoxy composites impacted directly by flame was established via ABAQUS code to simulate and discuss the thermal response, such as the field of temperature, density, decomposition degree and rate of decomposition, which has been proved to be valid by the comparison between the experimental and numerical results. In that, the process of polymer decomposition and pyrolysis gas diffusion were implemented in the UMATHT and USDFLD subroutines. This method of simulation is valuable for the application for aircraft industry, providing an effective numerical method for fireproof and thermal protection design of composite structure. Importantly, in this work the comprehension for thermal behavior of carbon epoxy laminates in fire was strengthened, and the following characteristics and regularities of the heat transfer and pyrolysis can be drawn.

1. Due to the effect of direction of layup and thermal conductivity on the heat transfer, in the insulated region, the areas affected along $\mathrm{x}$ and $\mathrm{y}$ directions are different, and temperature rise on the symmetric line in the $\mathrm{x}$ direction is higher than that in the $\mathrm{y}$ direction. Moreover, the temperature gradient on the symmetric line in the $\mathrm{x}$ direction is smaller than that in the $\mathrm{y}$ direction. In the thickness direction, the deeper away from the exposed surface, the smaller the peak of the rate of temperature rise.

2. With increasing heating time, the completely charring area in the impacted region expands towards the boundary between two regions, but the decomposition degree in the insulated region almost does not rise. When the same decomposition degree is achieved at different depths, the farther from the exposed surface, the lower the temperature. From another view, at any temperature, the closer to the exposed surface, the lower the decomposition degree.

3. With increasing depth, since there are different rates of temperature rise, the peak values of decomposition rate at different depths gradually decrease, as well as the time to reach the peak of decomposition rate gradually is delayed. In addition, the further away from the exposed surface, the lower the temperature at which the peak of the decomposition rate is reached.

Author Contributions: methodology, H.L.; formal analysis, H.L., X.H. and B.F.; writing-original draft preparation, N.W.; writing - review and editing, H.L. and B.F.; supervision, Z.F. and S.G.

Conflicts of Interest: The authors declare no conflict of interest.

\section{References}

1. Grigoriou, K.; Mouritz, A.P. Comparative assessment of the fire structural performance of carbon-epoxy composite and aluminium alloy used in aerospace structures. Mater Design 2016, 108, 699-706.

2. Grigoriou, K.; Mouritz, A.P. Influence of ply stacking pattern on the structural properties of quasi-isotropic carbon-epoxy laminates in fire. Composites Part a-Applied Science and Manufacturing 2017, 99, 113-120.

3. McKinnon, M.B.; Ding, Y.; Stoliarov, S.I.; Crowley, S.; Lyon, R.E. Pyrolysis model for a carbon fiber/epoxy structural aerospace composite. Journal of Fire Sciences 2017, 35 (1), 36-61.

4. Yu, Z.Q.; Zhou, A.X. Fiber Reinforced Polymer Composite Structures in Fire: Modeling and Validation. Mechanics of Advanced Materials and Structures 2013, 20 (5), 361-372.

5. Borri, Antonio; Castori, Giulio; Corradi, Marco; Speranzini Emanuela. Durability Analysis for FRP and SRG Composites in Civil Applications. Key Engineering Materials 2015, 624, 421-428.

6. Accident Report 2/2015 on the serious incident to Boeing B787-8, ET-AOP London Heathrow 12 July 2013.

7. Riccio, A.; Damiano, M.; Zarrelli, M.; Giordano, M.; Scaramuzzino, F. Simulating the Response of Composite Plates to Fire. Applied Composite Materials 2014, 21 (3), 511-524.

8. Federal Aviation Administration. Docket No. NM366 Special Conditions No. 25-348-SC Special conditions: Boeing 787-8 airplane; composite wing and fuel tank structure - fire protection requirements [S]. USA: Department of Transportation, 2007.

9. Federal Aviation Authority, (2009) Airworthiness Advisory Circular No: 20-107B. Composite Aircraft Structure, 09/08/2009. 
10. Henderson, J.B.; Wiebelt, J.A.; Tant, M.R. A model for the thermal response of polymer composite materials with experimental verification. J Compos Mater 1985, 19, 579-595.

11. Henderson, J.B.; Wiecek, T.E. A mathematical model to predict the thermal response of decomposing, expanding polymer composites. J Compos Mater 1987, 21, 373-393.

12. Henderson, J.B.; Wiecek, T.E. A Numerical Study of the Thermally-Induced Response of Decomposing, Expanding Polymer Composites. Waerme- und Stoffuebertragung, 1988, 22(5), 275-284.

13. Buch, J.D. Thermal Expansion Behavior of a Thermally Degrading Organic Matrix Composite. Thermomechanical Behavior of High-Temperature Composites, ASME Publication AD-04 (1982).

14. Mike, J.A.; Vizzini, A.J. Thermal response of fire-exposed composites. J. Compos. Technol. Res 1991, 13,145151.

15. Florio, J.J., et al. A Study of the Effects of the Assumption of Local-Thermal Equilibrium on the Overall Thermally-Induced Response of a Decomposing. Glass-Filled Polymer Composite. International Journal of Heat and Mass Transfer 1991, 34(1), 135-147.

16. Mouritz, A.P.; Feih, S.; Kandare, E.; Mathys, Z.; Gibson, A.G.; DesJardin P.E. Review of fire structural modelling of polymer composites. Composites Part A: Applied Science and Manufacturing 2009, 40(12), 1800-14. Available from: http://dx.doi.org/10.1016/j.compositesa.2009.09.001

17. Steven E. Boyd; John V. Bausano; Scott W. Case; and John J. Lesko. Mechanistic Approach to Structural Fire Modeling of Composites. Fire Technology, 2011, 47, 941-983.

18. Shi, S.; Li, L.; Fang, G.; Liang, J; Yi, F.; Lin, G. Three-dimensional modeling and experimental validation of thermomechanical response of FRP composites exposed to one-sided heat flux. Materials \& Design 2016, 99, 565-73. Available from: http://dx.doi.org/10.1016/j.matdes.2016.03.098.

19. Shi, S.; Li, L.; Liang, J. et al. Surface and volumetric ablation behaviors of SiFRP composites at high heating rates for thermal protection applications[J]. International Journal of Heat and Mass Transfer, 2016, 102:11901198.

20. Zhang, Z. Thermo-mechanical behavior of polymer composites exposed to fire. PhD thesis, Engineering Mechanics, The Virginia Polytechnic Institute and State University, Blacksburg, Virginia; 2010.

21. Rizk, G.; Legrand, V.; Khalil, K.; Casari, P.; Jacquemin, F. Durability of sandwich composites under extreme conditions: Towards the prediction of fire resistance properties based on thermo-mechanical measurements. Composite Structures 2018, 186, 233-45. Available from: http://dx.doi.org/10.1016/j.compstruct.2017.12.009

22. Luo, C.; DesJardin, P.E. Thermo-mechanical damage modeling of a glass-phenolic composite material. Compos. Sci. Technol 2007, 67, 1475-1488.

23. Luo, C. Mathematical modeling of thermo-mechanical damage of polymer matrix composites in fire. $\mathrm{PhD}$ thesis, Department of Mechanical and Aerospace Engineering, State University of New York at Buffalo, Buffalo, NY; 2010.

24. Luo, C.; Chen, L.; Lua, J.; Liu, P. Abaqus fire interface simulator toolkit (AFIST) for coupled fire and structural response prediction. 51st AIAA/ASME/ASCE/AHS/ASC structures, structural dynamics, and materials conference. Orlando, FL: AIAA 2010-2768; 2010.

25. Luo, C.; Lua, J.; DesJardin, P.E. Thermo-mechanical damage modeling of polymer matrix sandwich composites in fire. Composites Part A: Applied Science and Manufacturing 2012, 43(5), 814-21. Available from: http://dx.doi.org/10.1016/j.compositesa.2011.03.006

26. Juhyeong Lee; Thomas E. Lacy Jr.; Charles U. Pittman, Jr.; Michael S. Mazzola. Thermal Response of Carbon Fiber Epoxy Laminates with Metallic and Nonmetallic Protection Layers to Simulated Lightning Currents. POLYMER COMPOSITES 2018, 39 (S4), 2149-2166. Available from: https://doi.org/10.1002/pc.24502.

27. Tranchard, P.; Samyn, F.; Duquesne, S.; Thomas, M.; Estèbe, B.; Montès, J.L.; Bourbigot, S. Fire behavior of carbon fibre epoxy composite for aircraft: Novel test bench and experimental study. J. Fire Sci 2015, 33.

28. Tranchard, P.; Samyn, F.; Duquesne, S.; Estèbe, B.; Bourbigot, S.; Modelling Behaviour of a Carbon Epoxy Composite Exposed to Fire: Part I-Characterisation of Thermophysical Properties. Materials 2017, 10(5), 494. Available from: http://dx.doi.org/10.3390/ma10050494

29. Tranchard, P.; Samyn, F.; Duquesne, S.; Estèbe, B.; Bourbigot, S. Modelling behaviour of a carbon epoxy composite exposed to fire: Part II-comparison with experimental results. Materials 2017, 10, 470.

30. Mouritz, A.P.; Gibson, A.G. Fire Properties of Polymer Composite Materials, Springer, Dordrecht, Netherlands 2006, 133-158.

31. Ziqing Yu; Aixi Zhou. Fiber Reinforced Polymer Composite Structures in Fire: Modeling and Validation, Mechanics of Advanced Materials and Structures, 20:5, 361-372, DOI: 10.1080/15376494.2011.627639 
32. J.P. Firmo, M.R.T. Arruda, J.R. Correia, I.C. Rosa. Three-dimensional finite element modelling of the fire behaviour of insulated RC beams strengthened with EBR and NSM CFRP strips. Composite Structures. 183 (2018) 124-136.

33. $\mathrm{Xu} \mathrm{Y,} \mathrm{Yang} \mathrm{Y}$, Shen $\mathrm{R}$, et al. Thermal behavior and kinetics study of carbon/epoxy resin composites. Polymer Composites. 2019; 1-17. https://doi.org/10.1002/pc.25309.

34. Xu Y, Lv C, Shen R, Wang Z, Wang Q. Comparison of thermal and fire properties of carbon/epoxy laminate composites manufactured using two forming processes. Polymer Composites. 2020;1-9. https://doi.org/10.1002/pc.25675.

35. Dassault Systémes, ABAQUS 2017 Documentation. Available online: http://doku-abaqus.luis.unihannover.de/abaqus2017 (accessed on 3 June 2019).

36. Tant, M.R.; Henderson, J.B.; Boyer, C.T. Measurement and modelling of the thermochemical expansion of polymer composites. Composites 1985, 16(2), 121-126. Available at: http://dx.doi.org/10.1016/00104361(85)90618-4.

37. Tranchard, P.; Duquesne, S.; Samyn, F.; Estebe, B.; Bourbigot, S. Kinetic analysis of the thermal decomposition of a carbon fibre-reinforced epoxy resin laminate. Journal of Analytical and Applied Pyrolysis 2017, 126, 14-21.
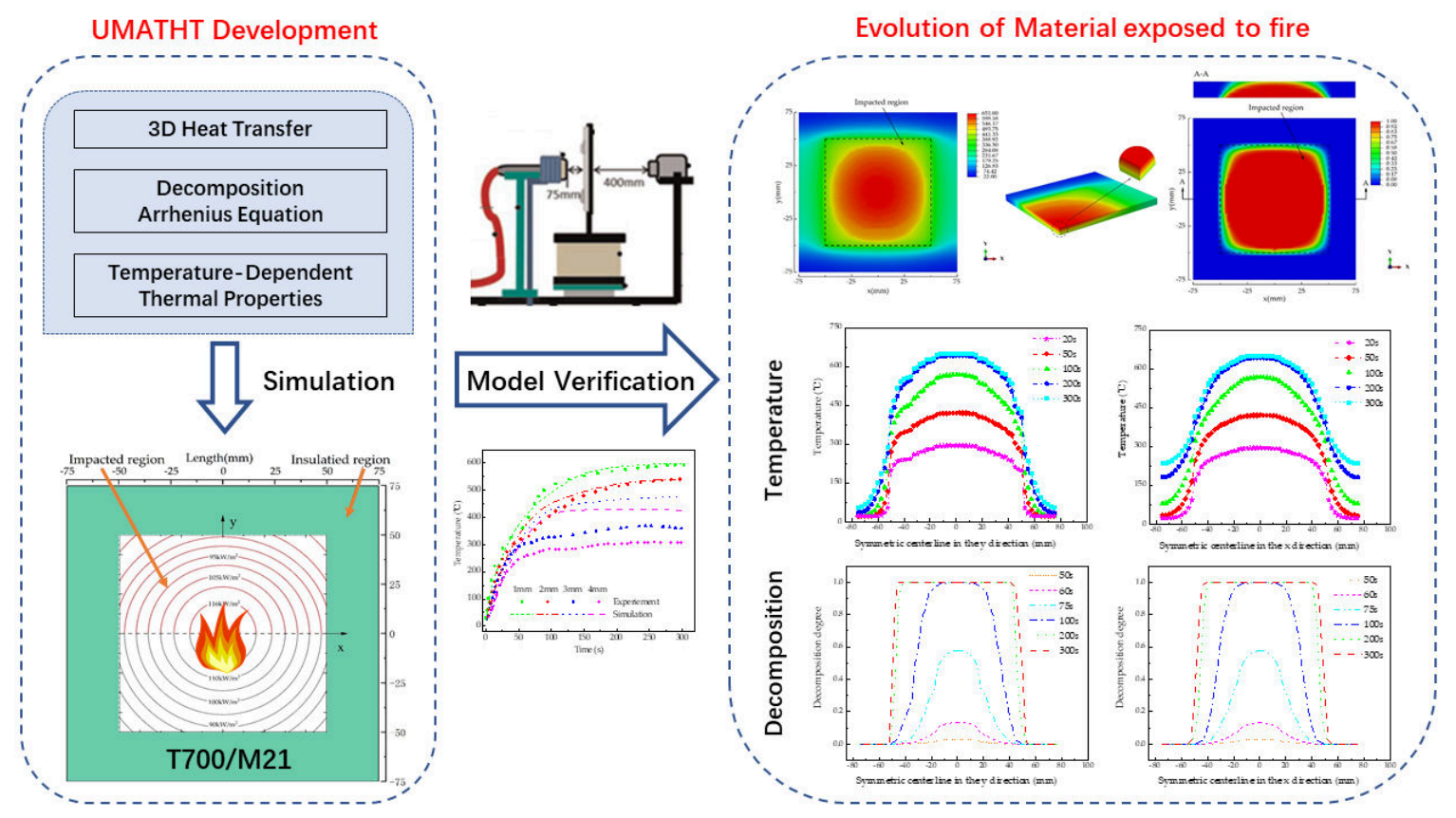

Graphical Abstract 
2020-08-12

Thermal response study of carbon epoxy laminates exposed to fire

Li, Han

Wiley

Li H, Fan B, Wang N, et al., (2020) Thermal response study of carbon epoxy laminates exposed to fire. Polymer Composites, Volume 41, Issue 11, November 2020, pp. 4757-4770 https://doi.org/10.1002/pc.25750

Downloaded from Cranfield Library Services E-Repository 